\title{
Long-term outcomes and prognostic factors of young patients with mucinous and signet-ring cell colorectal cancer
}

Rui Zhang, Jian Zhao, Jian Xu, Yuzhe Chen

Department of Colorectal Surgery, Cancer Hospital of China Medical University, Liaoning Cancer Hospital and Institute, Shenyang, Liaoning Province, China

Submitted: 6 June 2017

Accepted: 23 July 2017

Arch Med Sci 2020; 16 (2): 359-365

DOI: https://doi.org/10.5114/aoms.2020.93342

Copyright $\odot 2020$ Termedia \& Banach

\section{Abstract}

Introduction: The aim of the study was to assess the clinico-pathological features and prognosis of mucinous adenocarcinoma (MAC) and signet-ring cell carcinoma (SRC) in young colorectal cancer (CRC) patients.

Material and methods: We retrospectively evaluated the patient records of young patients with MAC and SRC (aged $\leq 40$ years) treated at the Cancer Hospital of China Medical University from January 2006 to December 2013. Kaplan-Meier analysis and log-rank testing were performed to estimate overall survival (OS). Subsequently a Cox proportional hazard model was used to calculate hazard ratios for the risk of death.

Results: A total of 90 young CRC patients $(M A C=69$ and $S R C=21)$ were included in the analysis during the study period. The overall cumulative 5 -year OS rate was $56.6 \pm 6 \%$. Estimated 5 -year OS was $58.1 \pm 7.7 \%$ for MAC and $31.3 \pm 12.9 \%$ for SRC $(p=0.018)$. On univariate analysis, metastatic disease, AJCC stage, adjuvant chemotherapy (CT), cycles of adjuvant CT, surgery type, lymphovascular invasion, perineural invasion, preoperative carcinoembryonic antigen (CEA) levels, and histologic type were significant prognostic factors for OS. In multivariate analysis, preoperative CEA levels and cycles of adjuvant CT were found to be independent prognostic factors for overall survival (hazard ratio $=2.47 ; 95 \% \mathrm{Cl}: 1.06-5.78, p=0.037$; hazard ratio $=$ $0.18 ; 95 \% \mathrm{Cl}: 0.05-0.62, p=0.007$, respectively).

Conclusions: A greater proportion of young patients with MAC and SRC present with advanced disease. Young patients with SRC have poorer prognosis than MAC. Preoperative CEA levels and cycles of adjuvant CT are two independent predictors of overall survival for young CRC patients with MAC and SRC.

Key words: colon, rectum, young, mucinous adenocarcinoma, signet-ring cell carcinoma.

\section{Introduction}

Colorectal cancer (CRC) is the second and third most commonly diagnosed cancer in males and females, respectively, with over 1.2 million new cancer cases and 608,700 deaths estimated to have occurred in 2008 [1]. Despite a slight decrease in its incidence and mortality during the past decades in China, CRC remains the fifth most common cancer, with an age standardized rate of 215.7 and 160.6 per 100,000 among men and women, respectively [2]. Generally, CRC is considered a dis-

\author{
Corresponding author: \\ Yuzhe Chen \\ Department of \\ Colorectal Surgery \\ Cancer Hospital \\ of China Medical \\ University \\ Liaoning Cancer \\ Hospital and Institute \\ 44 Xiaoheyan Road \\ Dadong District \\ Shenyang 110042 \\ Liaoning Province \\ China \\ Phone: +86 024-31916293 \\ Fax: +86 024-24315679 \\ E-mail: yuzhechen2017@ \\ sohu.com
}


ease of the older population with more than $90 \%$ patients diagnosed beyond 55 years [3]. In China, the age standardized rate of patients under 30 years of age and 30-44 years of age is 1.1 and 13.0 per 100,000 , which is significantly lower than that of patients aged 60 to 74 years $(90.9$ per $100,000)$ [2]. In recent years, a relative increase in the number of young patients diagnosed with CRC in the last decade has been reported in many countries [4]. Previous research has shown that young CRC patients have many unique characteristics with a relatively poorer prognosis, but these studies include all histologic types [5-9]. Although adenocarcinoma is the most common histologic subtype of CRC, mucinous and signet ring cell subtypes of adenocarcinoma are seen more frequently in young patients [10]. Additionally, Tawadros [11] reported that rectal cancer patients under 40 years of age were 3.6 times more likely to have signet cell histology. However, to our best knowledge, little information is available regarding the survival and prognostic factors of young patients $(\leq 40$ years) with mucinous adenocarcinoma (MAC) and signet-ring cell carcinoma (SRC). We thus conducted this retrospective study to specifically assess the long-term survival and prognostic factors for patients with MAC and SRC in this age group.

\section{Material and methods}

\section{Patients}

The medical records of the patients who underwent surgical resection at the Cancer Hospital of China Medical University from 2006 to 2013 with a diagnosis of colorectal MAC and SRC were retrieved from our department. A total of 90 patients with histopathologically confirmed colorectal MAC and SRC were identified with an age $\leq 40$ years and were included in the present analysis.

\section{Clinical variables and definitions}

Data including gender, age at diagnosis, date of diagnosis, tumor site, pathological diagnosis, tumor stage at the time of diagnosis, adjuvant chemotherapy, cycles of adjuvant chemotherapy, preoperative carcinoembryonic antigen (CEA) levels, and pathologic features ( $T$ stage, $N$ stage, $M$ stage, lymphovascular and perineural invasion) were obtained by reviewing the medical records. All tumors were staged according to the TNM staging system of the American Joint Committee on Cancer ( $7^{\text {th }}$ version, 2009). The tumor site was classified as colon or rectum. The cut-off CEA concentration was $5.0 \mathrm{ng} /$ day, which in our laboratory is the CEA concentration considered abnormal. In this study, patients $\leq 40$ years at diagnosis were referred to as young patients; the decision of 40 years as a cut off was based on previously pub- lished results [11-14]. Written informed consent was obtained from all patients and the study procedures were approved by the Ethical Committee of Cancer Hospital of China Medical University.

\section{Follow-up}

Patients were followed at 3-month intervals for 2 years, at 6-month intervals for the next 3 years, and annually thereafter. The date of the last follow-up was March 2016, which was mainly made with telephone calls. Recurrence was determined by clinical and radiologic examination or histologic confirmation. The main pattern of recurrence was recorded as the first site of detectable failure during the follow-up period. Disease-free survival (DFS) was the time from the surgery to the local or distant failure. Overall survival (OS) was calculated from surgery to death induced by all causes or end of follow-up.

\section{Statistical analysis}

Survival analysis was conducted using the Kaplan-Meier method. The comparison of the survival curves was performed by the log-rank test. A multivariable Cox-regression analysis was performed to identify predictive factors of overall survival. Every variable was analyzed by univariate analysis, in order to cover all potentially important predictors, then variables with $p \leq 0.10$ in univariate analysis were included in the multivariable analysis. This level was chosen to incorporate all potentially important predictor variables in the final modeling process. All sets of variables were analyzed: gender, pathologic $\mathrm{T}$ stage, $\mathrm{N}$ stage, $M$ stage, AJCC stage, adjuvant chemotherapy, cycles of adjuvant chemotherapy, tumor size, tumor location, lymphovascular invasion, perineural invasion, preoperative CEA levels, histological subtype (MAC versus SRC) and surgical types (radical versus palliative). Statistical analysis was performed using SPSS 16.0 software (SPSS Inc., Chicago, IL, United States). $P<0.05$ was considered statistically significant.

\section{Results}

\section{Patient characteristics}

The clinical and pathological characteristics of 90 patients (male-to-female ratio: $2.1: 1$ ) are summarized in Table I. The median age was 36 (20-40) years, and median follow-up time was 36.5 (3109) months. The treatment intention was radical for 65 (72.2\%) patients. The mean preoperative CEA level was $18.5 \mathrm{U} / \mathrm{ml}$ (range: 0.2-279 U/ml). A total of 83 patients received adjuvant chemotherapy after surgery excepting for 7 patients, and 77 patients received more than six cycles of ad- 
Table I. Clinicopathologic characteristics of 90 young patients with MAC and SRC

\begin{tabular}{|c|c|}
\hline Variable & Value \\
\hline Age, median (range) [years] & $36(20-40)$ \\
\hline \multicolumn{2}{|l|}{ Gender, $n$ : } \\
\hline Male & 69 \\
\hline Female & 21 \\
\hline \multicolumn{2}{|l|}{ Primary tumor location, $n$ : } \\
\hline Colon & 48 \\
\hline Rectum & 42 \\
\hline \multicolumn{2}{|l|}{ Histologic types, $n$ : } \\
\hline MAC & 69 \\
\hline SRC & 21 \\
\hline \multicolumn{2}{|l|}{ Adjuvant CT, $n$ : } \\
\hline Yes & 83 \\
\hline No & 7 \\
\hline \multicolumn{2}{|l|}{ Cycles of adjuvant CT, $n$ : } \\
\hline$\geq 6$ & 77 \\
\hline$<6$ & 13 \\
\hline \multicolumn{2}{|l|}{ Tumor size $[\mathrm{cm}]:$} \\
\hline$\geq 5$ & 45 \\
\hline$<5$ & 45 \\
\hline \multicolumn{2}{|l|}{ Surgical type, $n$ : } \\
\hline Radical & 65 \\
\hline Palliative & 25 \\
\hline \multicolumn{2}{|l|}{ T stage, $n$ : } \\
\hline $\mathrm{T} 1 / \mathrm{T} 2$ & 4 \\
\hline $\mathrm{T} 3 / \mathrm{T} 4$ & 86 \\
\hline \multicolumn{2}{|l|}{ N stage, $n$ : } \\
\hline NO & 23 \\
\hline N1 & 30 \\
\hline N2 & 37 \\
\hline \multicolumn{2}{|l|}{ Metastasis, $n$ : } \\
\hline No & 69 \\
\hline Yes & 21 \\
\hline \multicolumn{2}{|l|}{ Stage, $n$ : } \\
\hline $\mathrm{I} / \mathrm{II}$ & 15 \\
\hline III/IV & 75 \\
\hline \multicolumn{2}{|l|}{ Preoperative CEA levels [U/ml] } \\
\hline Mean (range ) & $18.5(0.2-279)$ \\
\hline \multicolumn{2}{|l|}{ Lymphovascular invasion, $n$ : } \\
\hline Positive & 41 \\
\hline Negative & 49 \\
\hline \multicolumn{2}{|l|}{ Perineural invasion, $n$ : } \\
\hline Positive & 40 \\
\hline Negative & 50 \\
\hline
\end{tabular}

$M A C$ - mucinous adenocarcinoma, $S R C$ - signet-ring cell carcinoma, CT - chemotherapy, $n$ - number, CEA - carcinoembryonic antigen. juvant chemotherapy (Table I). The median total number of lymph nodes harvested was 17 (range: 2-33).The number of patients with more than 12 lymph nodes was $76(84 \%$, Table I).

\section{Stage at diagnosis}

Of the 90 patients, 75 (83.3\%) presented with advanced-stage disease (stage III and IV). In particular, the proportion of distant metastasis was greater in the SRC group (38.0\%) compared with the mucinous group (20\%). The most common site of metastasis in the SRC group was peritoneum $(n=4,50 \%)$, followed by liver $(n=2,25 \%)$, while the common site of metastasis in MAC was liver $(n=7,50 \%)$, followed by peritoneum $(n=4$, 35.7\%) (Table II).

\section{Pattern of failure}

After a median follow-up of 36.5 months, the recurrence rate was significantly greater in the SRC group compared with the mucinous group $\left(52.4 \%\right.$ vs. $\left.26.1 \%, \chi^{2}=3.96, p=0.047\right)$. The specif-

Table II. Initial metastatic sites at diagnosis

\begin{tabular}{|lcc|}
\hline Metastatic sites & MAC, $n(\%)$ & SRC, $n(\%)$ \\
\hline Total & $14^{\#}$ & $8^{\star}$ \\
\hline Peritoneum & 5 & 4 \\
\hline Liver & 7 & 1 \\
\hline Lung & 1 & 0 \\
\hline Bone & 1 & 1 \\
\hline Lymph node & 1 & 1 \\
\hline Ovary & 3 & 1 \\
\hline
\end{tabular}

"One MAC patient initially diagnosed with lymph node and liver metastasis; one MAC patients initially diagnosed with lung, liver, bone and peritoneum metastasis. *One SRC patient diagnosed with liver and lymph node metastasis; $n$ - number.

Table III. Pattern of recurrence

\begin{tabular}{|c|c|c|c|}
\hline Stage & Recurrence sites & MAC, $n(\%)$ & SRC, $n(\%)$ \\
\hline \multirow[t]{8}{*}{ I to III } & Total & $18^{\#}$ & 11 \\
\hline & Local recurrence & 2 & 5 \\
\hline & Liver & 4 & 1 \\
\hline & Lung & 7 & 1 \\
\hline & Bone & 1 & 1 \\
\hline & Lymph node & 5 & 3 \\
\hline & Ovary & 1 & 0 \\
\hline & Chest wall & 1 & 0 \\
\hline
\end{tabular}

"One MAC patient relapsed with lymph node and chest wall metastasis; another MAC patient relapsed with liver, lung and bone metastasis; $n$ - number. 


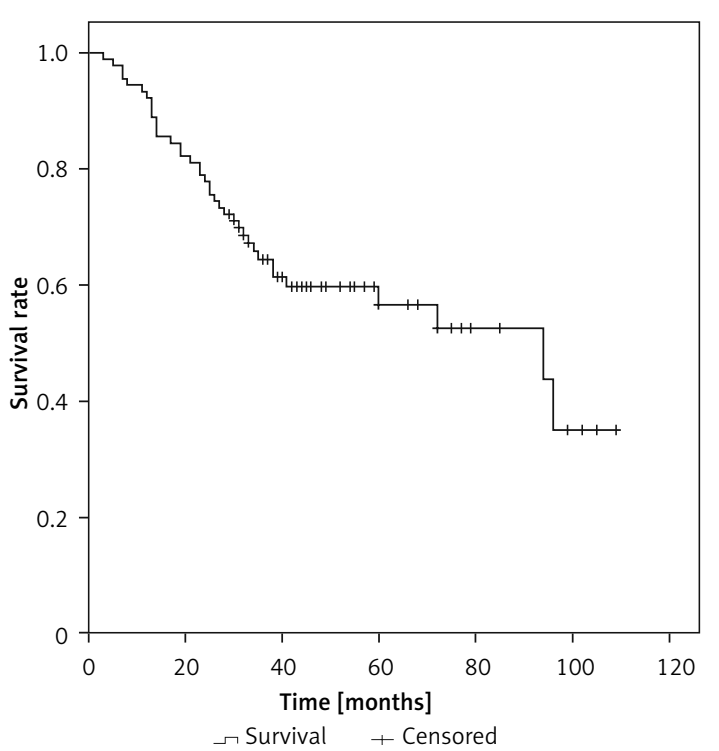

Figure 1. Kaplan-Meier curves for overall survival in the young SRC and MAC patients

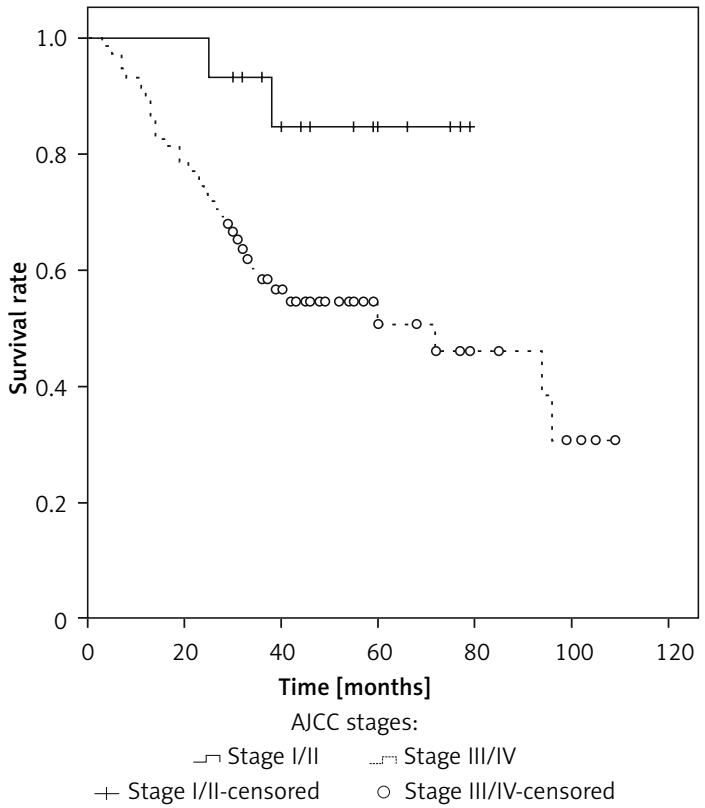

Figure 3. Overall survival stratified by AJCC stages in young patients

ic sites of recurrence are listed in Table III. The median DFS time for the SRC group was $17.0 \pm 11.2$ months, which was significantly shorter than the MAC group $67.8 \pm 6.0(p=0.025)$.

\section{Treatment outcome}

The median overall survival (OS) for the whole series was 94 months. The overall cumulative 5 -year OS rate was $56.6 \pm 6 \%$ (Figure 1). Estimated 5-year OS for MAC was significantly higher than SRC $(58.1 \pm 7.7 \%$ vs. $31.3 \pm 12.9 \%, p=0.018$, Figure 2). The cumulative 5 -year survival was $45.1 \%$ for women and $62.5 \%$ for men $(p=0.22$ ).

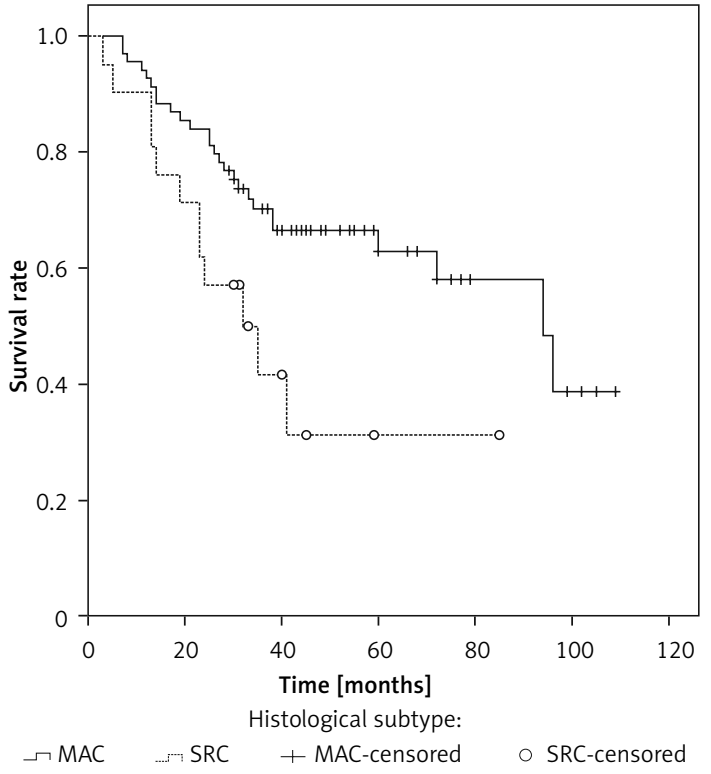

Figure 2. Overall survival stratified by histologic subtypes in young patients

Additionally, estimated 5-year OS for early stage (stage I/II) CRC patients was also significantly higher than for late stage (stage III/IV) CRC patients ( $p=0.024$, Figure 3 ).

\section{Analysis of prognostic factors for overall survival}

On univariate analysis, metastatic disease, AJCC stage, adjuvant chemotherapy (CT), cycles of adjuvant CT, surgery type, lymphovascular invasion, perineural invasion, preoperative CEA levels, and histologic type were significantly predictive for longer survival (Table IV), whereas gender, tumor size and $T$ stage were insignificant variables.

In the Cox proportional hazard model, preoperative CEA levels $(p=0.037)$ and cycles of adjuvant CT $(p=0.007)$ were independent prognostic factors for overall survival (Table IV).

\section{Discussion}

Primary colorectal MAC and SRC are two rare subtypes of colorectal cancer with a worse prognosis than classic adenocarcinoma [15-17], but the prognosis and clinical features of MAC and SRC in young patients remain undetermined. Although CRC occurs predominantly in older patients, there is a small number of CRC patients who present at a younger age [18]. However, no agreement has been reached regarding the age cutoff for the diagnosis of colorectal cancer in young patients. In the present study, we used 40 years as a cut-off, which is based on previously published results $[13,14,19,20]$. Our findings on gender differences are similar to all the published reports on colorectal cancer under age 40, with 
Table IV. Predictive factors for overall survival by univariate and multivariate analyses of the cohort $(n=90)$

\begin{tabular}{|c|c|c|c|c|c|c|}
\hline \multirow[t]{2}{*}{ Factors } & \multicolumn{3}{|c|}{ Univariate analysis } & \multicolumn{3}{|c|}{ Multivariate analysis } \\
\hline & $H R$ & $95 \% \mathrm{Cl}$ & $P$-value & $H R$ & $95 \% \mathrm{Cl}$ & $P$-value \\
\hline \multicolumn{7}{|l|}{ Gender: } \\
\hline Female & 1 & & & - & & \\
\hline Male & 0.67 & $0.35-1.28$ & 0.225 & - & - & - \\
\hline \multicolumn{7}{|c|}{ Tumor location: } \\
\hline Rectum & 1 & & & 1 & & \\
\hline Colon & 0.55 & $0.29-1.05$ & 0.072 & 0.57 & $0.26-1.21$ & 0.14 \\
\hline \multicolumn{7}{|c|}{ Histologic types: } \\
\hline MAC & 1 & & & 1 & & \\
\hline SRC & 2.28 & $1.13-4.59$ & 0.022 & 1.58 & $0.71-3.48$ & 0.26 \\
\hline \multicolumn{7}{|c|}{ Adjuvant CT: } \\
\hline No & 1 & & & 1 & & \\
\hline Yes & 0.22 & $0.088-0.53$ & 0.001 & 1.29 & $0.27-6.19$ & 0.75 \\
\hline \multicolumn{7}{|c|}{ Cycles of adjuvant CT: } \\
\hline$<6$ & 1 & & & 1 & & \\
\hline$\geq 6$ & 0.29 & $0.14-0.59$ & 0.001 & 0.18 & $0.05-0.62$ & 0.007 \\
\hline \multicolumn{7}{|c|}{ Tumor size $[\mathrm{cm}]$ : } \\
\hline$<5$ & 1 & & & 1 & & \\
\hline$\geq 5$ & 1.89 & $0.98-3.64$ & 0.056 & 1.23 & $0.55-2.74$ & 0.61 \\
\hline \multicolumn{7}{|c|}{ Surgical types: } \\
\hline Radical & 1 & & & 1 & & \\
\hline Palliative & 4.41 & $2.31-8.44$ & $<0.001$ & 1.40 & $0.37-5.28$ & 0.62 \\
\hline \multicolumn{7}{|l|}{ T stage: } \\
\hline $\mathrm{T} 1 / \mathrm{T} 2$ & 1 & & & & & \\
\hline $\mathrm{T} 3 / \mathrm{T} 4$ & 2.70 & $0.37-20.0$ & 0.33 & - & & \\
\hline N stage: & & & & - & - & - \\
\hline No & 1 & & & 1 & & \\
\hline $\mathrm{N} 1 / 2$ & 2.65 & $1.03-6.80$ & 0.043 & 1.15 & $0.27-4.86$ & 0.85 \\
\hline \multicolumn{7}{|l|}{ Metastasis: } \\
\hline No & 1 & & & 1 & & \\
\hline Yes & 5.15 & $2.65-10.02$ & $<0.001$ & 1.83 & $0.50-6.64$ & 0.36 \\
\hline \multicolumn{7}{|l|}{ Stage: } \\
\hline $\mathrm{I} / \mathrm{II}$ & 1 & & & 1 & & \\
\hline III/IV & 4.45 & $1.07-18.5$ & 0.04 & 1.84 & $0.26-12.9$ & 0.54 \\
\hline \multicolumn{7}{|c|}{ Preoperative CEA levels [U/ml]: } \\
\hline$<5$ & 1 & & & 1 & & \\
\hline$\geq 5$ & 3.23 & $1.69-6.17$ & $<0.001$ & 2.47 & $1.06-5.78$ & 0.037 \\
\hline \multicolumn{7}{|c|}{ Lymphovascular invasion: } \\
\hline Negative & 1 & & & 1 & & \\
\hline Positive & 3.20 & $1.62-6.29$ & 0.001 & 1.36 & $0.53-3.47$ & 0.52 \\
\hline \multicolumn{7}{|c|}{ Perineural invasion: } \\
\hline Negative & 1 & & & 1 & & \\
\hline Positive & 1.99 & $1.04-3.81$ & 0.038 & 1.38 & $0.53-3.60$ & 0.50 \\
\hline
\end{tabular}

$H R$ - hazard ratio, $\mathrm{Cl}$ - confidence interval, MAC - mucinous adenocarcinoma, SRC - signet-ring cell carcinoma, CT - chemotherapy, CEA - carcinoembryonic antigen. 
the male-to-female ratio of $2.1: 1$. On the other hand, in this study male patients had a better outcome than female patients, but the difference was not significant $(p=0.22)$. Another important finding of this study is that young MAC and SRC patients presented with advanced-stage disease. Berut et al. [3] reported that CRC in young patients was often diagnosed in advanced stages. Nitsche et al. [16] also found that MAC and SRC patients had higher stages of the primary tumor and lymph node involvement. Consistently with previous results, $75(83.3 \%)$ of 90 patients presented with stage III and IV disease. Peritoneal dissemination is a common metastatic site of CRC, which is present in approximately 7\% of CRC patients at the time of diagnosis [21]. Several risk factors for the development of peritoneal metastases have been identified, including right-sided tumor, advanced T-stage, advanced $\mathrm{N}$-stage, poor differentiation grade, and younger age at diagnosis [22]. In concordance with the literature, our study showed that the peritoneum is the most common site of metastasis in young patients with SRC and MAC.

Most published studies suggest that MAC and SRC are associated with poor outcomes. Messerini et al. [23] reported that the overall 5-year survival rate of those with SRC of the colorectum was $9.1 \%$, and survival was influenced significantly by tumor stage. Nitsche et al. [16] found that 5-year cause-specific survival was $61 \pm 3 \%$ for MAC and $21 \pm 8 \%$ for SRC. Chen et al. [17] also reported that the 5-year overall survival rates of patients with SRC and MAC were $11.9 \%$ and $49.4 \%$, respectively. Lee et al. [24] reported that 3- and 5-year survival rates in the SRC group were $33.7 \%$ and $25.3 \%$, respectively. The overall survival rate of patients with SRC was significantly poorer than that of patients with mucinous or poorly differentiated adenocarcinoma. The findings of the present study are consistent with these published reports. Based on these findings, SRC patients could be regarded as a different clinical entity due to its poor prognosis [16]. Indeed, carcinogenetic factors, tumor growth, and development have been described to be different in SRC than in non-SRC tumors [25]. Additionally, we conducted a multivariate regression analysis and found a survival advantage for patients presenting with normal preoperative CEA levels and those who received more than six cycles of adjuvant CT. Based on our findings, sufficient cycles of adjuvant CT are recommended for young MAC and SRC patients with high risk factors.

Distant failure has been the predominant failure pattern after the routine use of surgery and adjuvant chemotherapy in patients with locally advanced CRC patients. In our series, distant metastasis is the most common type of failure in MAC patients, seen in 16 patients. The lung, liver and lymph nodes have been the most common sites of distant recurrence in patients with MAC. Interestingly, local recurrence is the most common type of failure in SRC patients, seen in 5 patients. The lymph nodes are the most common sites of distant recurrence in patients with SRC. This findings of the present study are consistent with previous results. Lee et al. [26] reported that recurrence after resection in the SRC group was significantly higher than that of the non-mucinous adenocarcinoma group (33.3\% vs. $10.7 \%, p=0.038$ ).

The current study is limited by its retrospective design, the relatively small number of young SRC and MAC patients and possible patient selection bias. However, it appears difficult to conduct a randomized trial for this rare disease in young patients. In addition, this is the first study, to our best knowledge, specifically assessing the longterm survival and prognostic factors of young patients with SRC and MAC.

In conclusion, a greater proportion of young patients with MAC and SRC present with advanced disease. Young patients with SRC have poorer prognosis than MAC. The most common type of failure in young SRC is local recurrence, while it is lung metastasis for MAC. Preoperative CEA levels and cycles of adjuvant CT are two independent predictors of overall survival for young CRC patients with MAC and SRC.

\section{Acknolwedgments}

This work was supported by the National Natural Science Fund from the National Natural Science Foundation of China (grant nos. 81672427), The project was sponsored by Liaoning Bai Qian Wan Talents Program" [2017] No. 45, and the project of Liaoning Clinical Research Center for Colorectal Cancer (grant no. 2015225005), Clinical Capability Construction Project for Liaoning Provincial Hospitals (LNCCC-D42-2015)

\section{Conflict of interest}

The authors declare no conflict of interest.

\section{References}

1. Jemal A, Bray F, Center MM, Ferlay J, Ward E, Forman D. Global cancer statistics. CA Cancer J Clin 2011; 61: 69-90.

2. Chen $W$, Zheng R, Baade PD, et al. Cancer statistics in China, 2015. CA Cancer J Clin 2016; 66: 115-32.

3. Berut M, Mik M, Kedzia-Berut R, et al. Colorectal cancer in young and elderly patients. Pol Przegl Chirurg 2013; 85: 446-51.

4. O'Connell JB, Maggard MA, Liu JH, Etzioni DA, Livingston $\mathrm{EH}$, Ko CY. Rates of colon and rectal cancers are increasing in young adults. Am Surgeon 2003; 69: 866-72.

5. Murata A, Akiyoshi T, Ueno M, et al. Clinicopathological characteristics of young patients with sporadic colorectal cancer. Surg Today 2016; 46: 1166-75. 
6. Meyer JE, Cohen SJ, Ruth KJ, Sigurdson ER, Hall MJ. Young age increases risk of lymph node positivity in early-stage rectal cancer. J Natl Cancer Inst 2016; 108: djv284.

7. Goldvaser H, Purim O, Kundel Y, et al. Colorectal cancer in young patients: is it a distinct clinical entity? Int I Clin Oncol 2016; 21: 684-95.

8. Ashktorab H, Vilmenay K, Brim H, Laiyemo AO, Kibreab A, Nouraie M. Colorectal cancer in young African Americans: is it time to revisit guidelines and prevention? Dig Dis Sci 2016; 61: 3026-30.

9. Li J, Wang Z, Yuan X, Xu L, Tong J. The prognostic significance of age in operated and non-operated colorectal cancer. BMC Cancer 2015; 15: 83.

10. Tan Y, Fu J, Li X, et al. A minor ( $<50 \%)$ signet-ring cell component associated with poor prognosis in colorectal cancer patients: a 26-year retrospective study in China. PLoS One 2015; 10: e0121944.

11. Tawadros PS, Paquette IM, Hanly AM, Mellgren AF, Rothenberger DA, Madoff RD. Adenocarcinoma of the rectum in patients under age 40 is increasing: impact of signet-ring cell histology. Dis Colon Rectum 2015; 58: 474-8.

12. Soliman AS, Bondy ML, Levin B, et al. Colorectal cancer in Egyptian patients under 40 years of age. Int J Cancer 1997; 71: 26-30.

13. Keswani SG, Boyle MJ, Maxwell JP, et al. Colorectal cancer in patients younger than 40 years of age. Am Surg 2002; 68: 871-6.

14. Al-Jaberi TM, Yaghan RJ, El-Heis HA. Colorectal cancer in young patients under 40 years of age. Comparison with old patients in a well defined Jordanian population. Saudi Med Jl 2003; 24: 871-4.

15. Park JS, Huh JW, Park YA, et al. Prognostic comparison between mucinous and nonmucinous adenocarcinoma in colorectal cancer. Medicine 2015; 94: e658.

16. Nitsche U, Zimmermann A, Spath C, et al. Mucinous and signet-ring cell colorectal cancers differ from classical adenocarcinomas in tumor biology and prognosis. Ann Surg 2013; 258: 775-82..

17. Chen JS, Hsieh PS, Chiang JM, et al. Clinical outcome of signet ring cell carcinoma and mucinous adenocarcinoma of the colon. Chang Gung Med J 2010; 33: 51-7.

18. Isbister WH, Fraser J. Large-bowel cancer in the young: a national survival study. Dis Colon Rectum 1990; 33: 363-6.

19. Lin JT, Wang WS, Yen CC, et al. Outcome of colorectal carcinoma in patients under 40 years of age. J Gastroenterol Hepatol 2005; 20: 900-5.

20. Makela JT, Kiviniemi H. Clinicopathological features of colorectal cancer in patients under 40 years of age. Int J Colorectal Dis 2010; 25: 823-8.

21. Goere D, Allard MA, Honore C, Dumont F, Elias D. Incidence and prognosis of synchronous colorectal carcinomatosis. Future Oncol 2013; 9: 541-9.

22. Lemmens VE, Klaver YL, Verwaal VJ, Rutten HJ, Coebergh JW, de Hingh $\mathrm{IH}$. Predictors and survival of synchronous peritoneal carcinomatosis of colorectal origin: a population-based study. Int J Cancer 2011; 128: 271725.

23. Messerini L, Palomba A, Zampi G. Primary signet-ring cell carcinoma of the colon and rectum. Dis Colon Rectum 1995; 38: 1189-92.

24. Lee WS, Chun HK, Lee WY, et al. Treatment outcomes in patients with signet ring cell carcinoma of the colorectum. Am J Surg 2007; 194: 294-8.

25. Hartman DJ, Nikiforova MN, Chang DT, et al. Signet ring cell colorectal carcinoma: a distinct subset of mu- cin-poor microsatellite-stable signet ring cell carcinoma associated with dismal prognosis. Am J Surg Pathol 2013; 37: 969-77.

26. Lee HS, Soh JS, Lee $S$, et al. Clinical features and prognosis of resectable primary colorectal signet-ring cell carcinoma. Intest Res 2015; 13: 332-8. 